NATIONAL LABORATORY

MANAGED BY UT-BATTELLE

FOR THE DEPARTMENT OF ENERGY

\title{
ASSESSMENT OF CAVITATION-EROSION RESISTANCE OF 316LN STAINLESS STEEL FOLLOWING A NITRO- CARBURIZING SURFACE TREATMENT
}

S. J. Pawel

November 2009

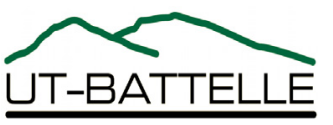




\section{DOCUMENT AVAILABILITY}

Reports produced after January 1, 1996, are generally available free via the U.S. Department of Energy (DOE) Information Bridge.

Web site http://www.osti.gov/bridge

Reports produced before January 1, 1996, may be purchased by members of the public from the following source.

National Technical Information Service

5285 Port Royal Road

Springfield, VA 22161

Telephone 703-605-6000 (1-800-553-6847)

TDD 703-487-4639

Fax 703-605-6900

E-mail info@ntis.fedworld.gov

Web site http://www.ntis.gov/support/ordernowabout.htm

Reports are available to DOE employees, DOE contractors, Energy Technology Data Exchange (ETDE) representatives, and International Nuclear Information System (INIS)

representatives from the following source.

Office of Scientific and Technical Information

P.O. Box 62

Oak Ridge, TN 37831

Telephone 865-576-8401

Fax 865-576-5728

E-mail reports@adonis.osti.gov

Web site http://www.osti.gov/contact.html

This report was prepared as an account of work sponsored by an agency of the United States Government. Neither the United States Government nor any agency thereof, nor any of their employees, makes any warranty, express or implied, or assumes any legal liability or responsibility for the accuracy, completeness, or usefulness of any information, apparatus, product, or process disclosed, or represents that its use would not infringe privately owned rights. Reference herein to any specific commercial product, process, or service by trade name, trademark, manufacturer, or otherwise, does not necessarily constitute or imply its endorsement, recommendation, or favoring by the United States Government or any agency thereof. The views and opinions of authors expressed herein do not necessarily state or reflect those of the United States Government or any agency thereof. 
ORNL/TM-2009/

Materials Science and Technology Division

\title{
ASSESSMENT OF CAVITATION-EROSION RESISTANCE OF 316LN STAINLESS STEEL FOLLOWING A NITRO-CARBURIZING SURFACE TREATMENT
}

\author{
S. J. Pawel
}

Date Published: November 2009

Prepared for the U.S. Department of Energy

Spallation Neutron Source

Prepared by

OAK RIDGE NATIONAL LABORATORY

Oak Ridge, Tennessee 37831-6285

managed by

UT-Battelle, LLC

for the

U.S. DEPARTMENT OF ENERGY

under contract DE-AC05-00OR22725 



\section{CONTENTS}

Page

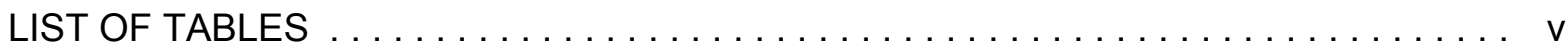

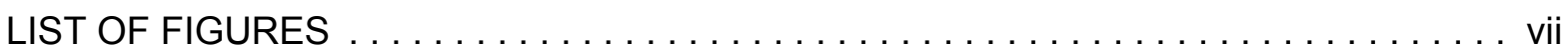

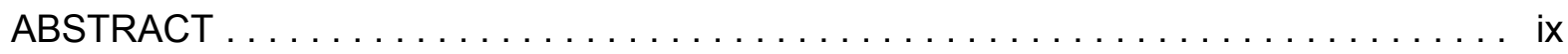

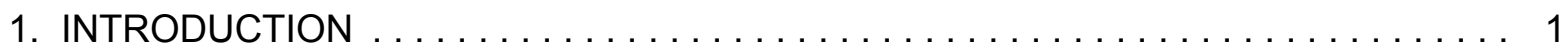

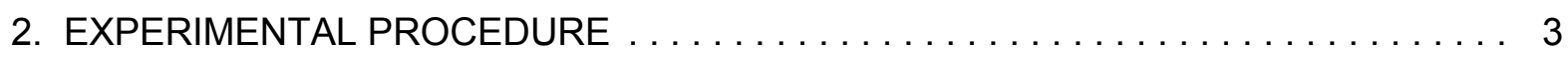

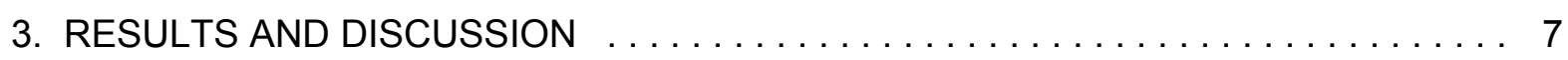

4. SUMMARY AND CONCLUSIONS ............................ 25

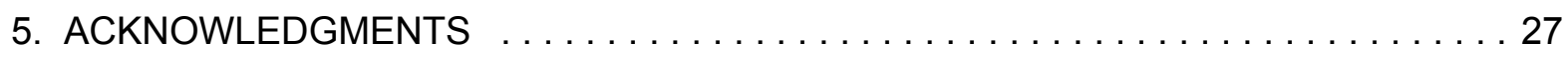

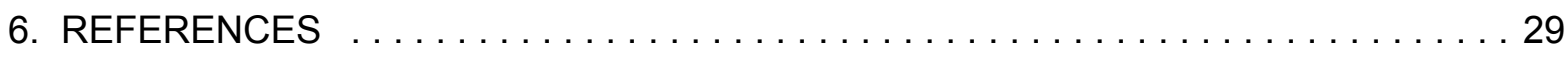





\section{LIST OF TABLES}

\section{TABLE}

Page

1. Composition (wt \%) of type 316LN stainless steel used as a

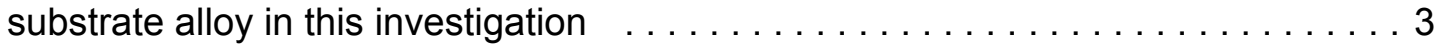





\section{LIST OF FIGURES}

Figure

Page

1. Weight loss as a function of sonication time in mercury at $25^{\circ} \mathrm{C}$ for annealed 316LN following the Melonite ${ }^{\circledR} \mathrm{QPQ}$ treatment

2. Cross-section of the side of a $316 \mathrm{LN}$ cavitation specimen

following M-layer treatment

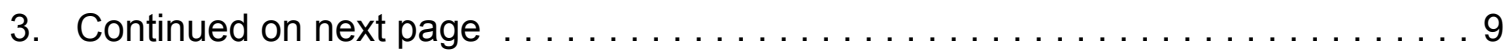

3. SEM images of the $316 \mathrm{LN}+\mathrm{M}$-layer test surface following $1 \mathrm{~h}$ sonication in mercury $\ldots \ldots \ldots \ldots \ldots \ldots \ldots \ldots \ldots \ldots \ldots \ldots \ldots \ldots \ldots \ldots \ldots \ldots \ldots$

4. As-treated (unexposed M-layer) test surface compared to surfaces following 1 - and $3-\mathrm{h}$ sonication exposures in mercury $\ldots \ldots \ldots \ldots \ldots \ldots$

5. SEM images of the 316LN + M-layer test surface following (a) $3 \mathrm{~h}$

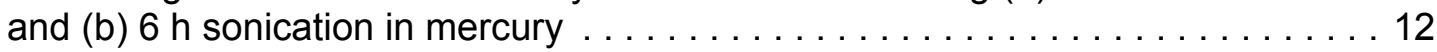

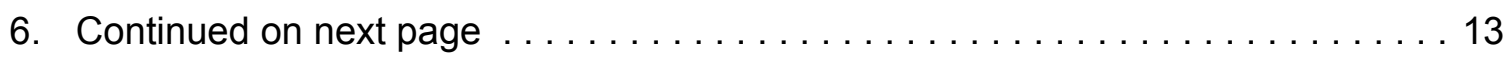

6. SEM images of the $316 \mathrm{LN}+$ M-layer test surface following $12 \mathrm{~h}$

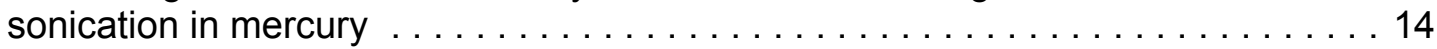

7. Cavitation test surface showing mercury remaining at locations sufficiently cratered to penetrate the M-layer and expose substrate $316 \mathrm{LN}$

8. SEM images of the $316 \mathrm{LN}+\mathrm{M}$-layer test surface following $20 \mathrm{~h}$ sonication in mercury

9. Cross section of test specimen following $12 \mathrm{~h}$ sonication in mercury $\ldots \ldots \ldots 17$

10. Higher magnification view of the surface crater indicated in the white highlight box from Fig. 9

11. Cross section of test specimen following $12 \mathrm{~h}$ sonication in mercury - a different area on the same test surface depicted in Figs. 9 and 10

12. Another cross section of the test specimen surface following

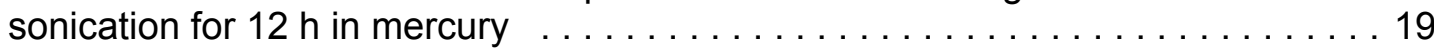

13. Cross sections of test specimen following $20 \mathrm{~h}$ sonication in mercury $\ldots \ldots \ldots 21$

14. Depth as a function of sonication time in mercury for eight individual craters $\ldots 22$ 
15. Comparison of total weight loss as a function of sonication time in mercury for bare/untreated 316LN stainless steel and for the same alloy with different surface treatments

16. Diamond Pyramid Hardness (DPH) as a function of distance from the surface for M-layer and K-layer treatments 


\begin{abstract}
A nitro-carburizing surface treatment known domestically as the Melonite ${ }^{\circledR}$ process was applied to type 316LN stainless steel test pieces and exposed to sonication conditions in mercury using a vibratory horn technique. Cavitation-erosion damage was evaluated for extended exposures and compared to other surface treatments on the same substrate alloy. The results indicate that the Melonite $®$ process substantially retards weight loss and crater development for extended periods, but gradually is eroded/destroyed leading to exposure of the substrate and cavitation-erosion behavior similar to untreated specimens.

Compared with other surface treatments, cavitation-erosion results indicate that specimens treated with Melonite ${ }^{\circledR}$ perform similarly to specimens treated with a simple nitriding process. Neither the simple nitriding nor the Melonite ${ }^{\circledR}$ treatment is quite as effective as a previously evaluated low temperature carburizing treatment, the latter being about a factor of three better than Melonite $®$ in terms of weight loss during sonication in mercury.
\end{abstract}





\section{INTRODUCTION}

Thermal-shock induced pressure waves are expected within the Spallation Neutron Source (SNS) target vessel due to the interaction between the incoming pulsed proton beam and the liquid mercury target. After reflection of the pressure waves from the containment surfaces, negative pressure transients sufficient to cavitate the liquid mercury are anticipated. Some of the energy released during the collapse of cavitation voids will result in a jetting action of liquid mercury at extreme velocity that - for events relatively near containment surfaces - can potentially reduce wall thickness to unacceptable values via cavitation-erosion or pitting.

Type 316L/316LN stainless steel was selected as the target containment material for the SNS due to a combination of well-characterized behavior in a neutron radiation environment, including absence of a ductile-brittle transition, and good compatibility with mercury over a range of conditions. However, annealed 316/316LN has been shown to be susceptible to potentially significant pitting and erosion damage due to cavitation in mercury in laboratory tests using a split Hopkinson pressure bar apparatus, ${ }^{1}$ in-beam exposure ${ }^{2-3}$ and a vibratory horn. ${ }^{4-7}$ A variety of surface treatments for $316 \mathrm{LN}$ intended to improve resistance to cavitation have also been evaluated and, based on vibratory horn testing, the most successful of these examined to date has been a low-temperature gas carburizing treatment termed Kolsterising ${ }^{\circledR}$ (trademark of the Bodycote Company, Apeldoorn, Netherlands). In this treatment, several weight percent carbon is diffused into the substrate stainless steel to a depth of nominally $33 \mu \mathrm{m}$. Because the carburizing is accomplished at a temperature well below that associated with precipitation of chromium carbides (occurs rapidly at $550-750^{\circ} \mathrm{C}$ ), the carbon remains in solid solution resulting in a significantly hardened surface that simultaneously retains good toughness. Further, because the hardened surface results in a diffusion gradient into the substrate, there is no distinct interface at which properties change in step-function fashion. Thus, there is no discreet initiation point for failure (via loss of adhesion and cracking/spalling) as might be the case for surface coatings that do not penetrate and/or intimately bond with the substrate. As measured by weight loss and surface profile development of specimens tested for extended sonication times with a vibratory horn in mercury, Kolsterizing ${ }^{\circledR}$ substantially improves cavitation resistance of annealed $316 \mathrm{LN} .^{8-9}$

Recently, a proprietary surface hardening process termed Melonite ${ }^{\circledR}$ (trademark of Durferrit $\mathrm{GmbH}$, Mannheim, Germany; the same process is also known as Tenifer $\AA$ and 
Tufftride ${ }^{\circledR}$ in other worldwide markets) that is potentially suitable for stainless steels has come to the attention of the SNS staff. The process involves nitro-carburizing - primarily diffusion of nitrogen and lesser amounts of carbon and oxygen into the substrate in a salt bath at temperatures near $500-550^{\circ} \mathrm{C}$ - to generate a surface layer of primarily single phase epsilon iron nitride above a diffusion layer with elevated solid solution nitrogen content. The primary (advertised) purpose of the Melonite ${ }^{\circledR}$ treatment is to improve corrosion and wear resistance, but its apparent similarities to the Kolsterizing ${ }^{\circledR}$ process suggest potential improvement of cavitation-erosion resistance as well. As a result, test pieces of $316 \mathrm{LN}$ identical to those used in many previous experiments for SNS were treated with the Melonite ${ }^{\circledR}$ process and sonicated in mercury with the vibratory horn for direct comparison with Kolsterizing $®$ and other surface treatments. 


\section{EXPERIMENTAL PROCEDURE}

The composition of the mill-annealed type $316 \mathrm{LN}$ stainless steel used in this investigation - identical to that used for previous cavitation-erosion experiments in mercury for the SNS - is reported in Table 1. As in previous sample fabrication, the test face of each specimen was machined parallel to the rolling direction of the original plate material to limit the number of inclusion stringers - relatively few in any case - intersecting the specimen surface and potentially giving rise to atypical cavitation response.

Table 1. Composition (wt \%) of type $316 \mathrm{LN}$ stainless steel used as a substrate alloy in this investigation. Values taken from certified mill report.

\begin{tabular}{cc}
\hline Element & 316LN (wrought) \\
\hline $\mathrm{C}$ & 0.009 \\
$\mathrm{~N}$ & 0.11 \\
$\mathrm{Cr}$ & 16.31 \\
$\mathrm{Ni}$ & 10.2 \\
$\mathrm{Mo}$ & 2.07 \\
$\mathrm{Mn}$ & 1.75 \\
$\mathrm{Cu}$ & 0.23 \\
$\mathrm{Co}$ & 0.16 \\
$\mathrm{P}$ & 0.029 \\
$\mathrm{Si}$ & 0.39 \\
$\mathrm{~S}$ & 0.002 \\
$\mathrm{Fe}$ & balance
\end{tabular}

Test specimens machined from mill-annealed 316LN were subjected to the Melonite $\circledR$ QPQ treatment in a domestic commercial facility. The process involves immersion in a salt bath at $500-550^{\circ} \mathrm{C}$ for typically $1-2 \mathrm{~h}$ to enrich the surface of the component with nitrogen and, to a lesser extent, carbon. The near-surface layer formed by this high-temperature diffusion process is typically termed the compound zone or the "white layer" in Melonite ${ }^{\circledR}$ literature, and according to the developers it consists of essentially single phase epsilon iron nitride $10-25 \mu \mathrm{m}$ thick and a composition of up to $8-9 \%$ nitrogen and $1 \%$ carbon. Beneath the compound zone (that is, deeper into the work piece), a diffusion zone enriched in nitrogen forms. Depending on the specific alloy composition, salt bath time and 
temperature, and cooling rate following treatment, the diffusion zone may approach $1 \mathrm{~mm}$ in thickness in low alloy materials but it is typically much thinner in stainless alloys. The nitrogen content of the diffusion zone is lower than that in the compound zone, with the nitrogen primarily present in solid solution or as fine nitride precipitates.

The specific designation "QPQ" associated with the treatment indicates the procedure follows a quench-polish-quench sequence. Although specific details are not known to the author, the Melonite $®$ literature indicates that following initial salt bath treatment, the component is quenched (quickly cooled) and then the surfaces of interest are polished followed by reheating and quenching. In general, this procedure results in a very uniform black surface coloration with maximum surface finish and low coefficient of friction (required for wear applications).

Like all previous evaluations in this program, cavitation-erosion tests were performed using a titanium vibratory horn and the general test methodology described in ASTM G-32. ${ }^{10}$ Each test specimen had a surface area of $180 \mathrm{~mm}^{2}$ exposed to cavitation conditions (other specimen details previously reported, ${ }^{7}$ and was attached to the vibratory horn tip via a threaded shank. In each test, the horn tip oscillated at a fixed frequency of $20 \mathrm{kHz}$ with a peak-to-peak vibrational amplitude of $25 \mu \mathrm{m}$. The test specimen surface on the horn tip was immersed about $2 \mathrm{~mm}$ into the pure mercury pool in the center of a jacketed stainless steel container (about $10 \mathrm{~cm}$ diameter, $11 \mathrm{~cm}$ depth of mercury). A water/glycol mixture was circulated through the jacket to maintain a constant temperature of $25-26^{\circ} \mathrm{C}$ during sonication. Periodically, cheesecloth was used to skim the mercury surface to remove floating oxide and/or test debris.

A total of four cavitation specimens were treated with the Melonite process. Based on comparison of pre- and post-process specimen weight, two specimens were found to gain a modest amount (1 to $1.5 \mathrm{mg}$ ) and two were found to lose a modest amount of weight (about $1 \mathrm{mg}$ ). Since the overall treatment process is a balance of weight loss associated with the cleaning step(s) and weight gain associated with the uptake of nitrogen and carbon, it is not practical to attempt to assign significance to a particular weight gain or loss. However, the ostensibly duplicate specimens chosen for evaluation were selected to be the specimens exhibiting the greatest net wet gain and loss, respectively. As will be seen in the next section, the cavitation-erosion results for these two specimens were indistinguishable, and thus no impact of the range of weight change was associated with these specimens and only these two were included in the testing. 
Following sonication, the test specimens were ultrasonically cleaned sequentially in (1) a commercial aqueous solution containing dissolved sulfur species to chemically bind residual mercury, (2) distilled water, and (3) acetone, followed by forced air drying after each step. Specimens were then weighed and subsequently examined with an optical microscope to assess the cavitation-erosion surface profile and any pitting damage. In both cases, the calibrated fine focus feature of the microscope stage was used to estimate the distance between high and low points in a given field of view to evaluate relative surface profile and pit depth. Periodically, specimens were also examined with the scanning electron microscope (SEM) and eventually (at the end of total intended test duration) sectioned for metallographic evaluation of the cross section. 



\section{RESULTS AND DISCUSSION}

Weight loss as a function of sonication time for two annealed 316LN specimens that received the Melonite ${ }^{\circ}$ QPQ treatment (hereafter referred to as the M-layer) is shown in Fig. 1. Results for the two specimens are very similar, and the average weight loss rate is roughly constant near $2.5 \mathrm{mg} / \mathrm{h}$ over the first 12-14 h exposure, after which weight loss accelerates as the protective quality of the M-layer fails over an increasingly larger specimen area. As a point of comparison, identical specimens treated via Kolsterising ${ }^{\circledR}$ (hereafter referred to as the K-layer) exhibited an approximately constant weight loss rate of $0.8 \mathrm{mg} / \mathrm{h}$ over periods of at least $20 \mathrm{~h}$ exposure under these cavitation conditions.

Additional comparison of the M-layer with other surface treatments appears later within this Section.

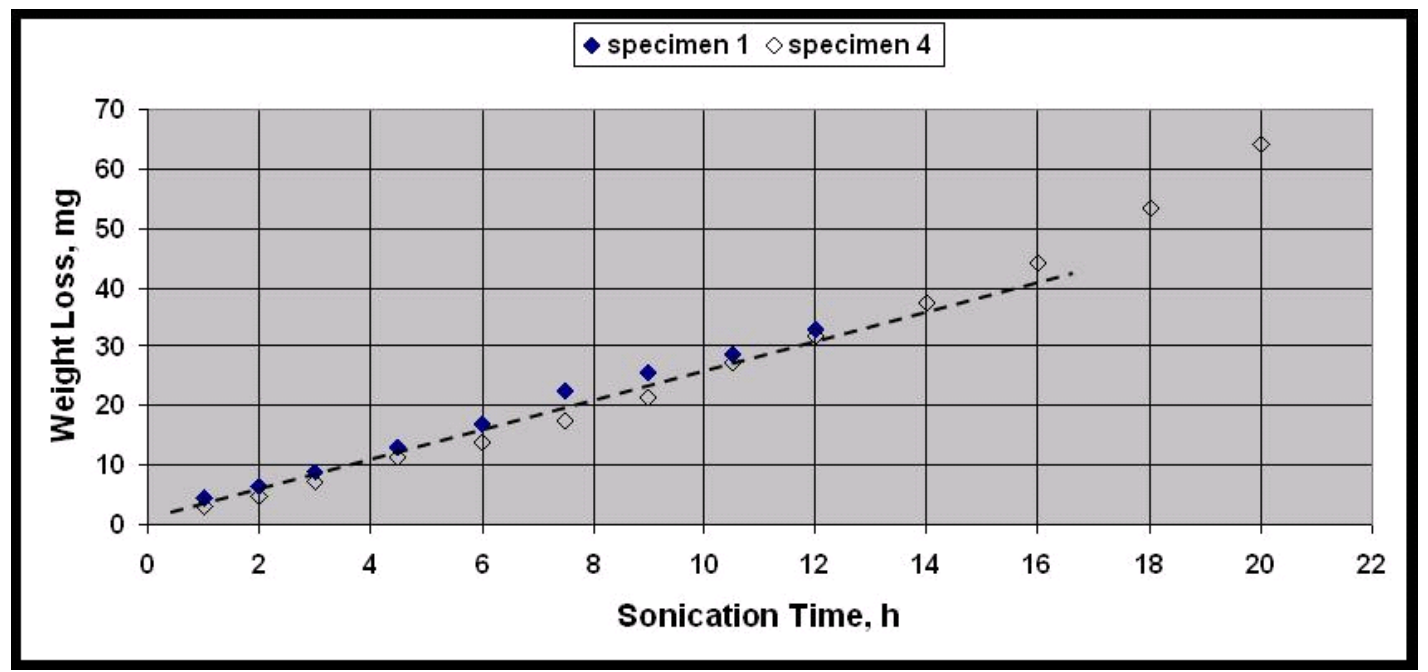

Fig. 1. Weight loss as a function of sonication time in mercury at $25^{\circ} \mathrm{C}$ for annealed 316LN following the Melonite ${ }^{\circledR}$ QPQ treatment.

Figure 2 shows a cross section of a portion of a treated sample (taken from the side of the specimen, which is unaffected by the sonication exposures), and it reveals some key features of the M-layer. The total M-layer thickness - made evident by the different etching characteristics of the nitrogen-doped area compared to the base metal - is about $32 \mu \mathrm{m}$ in the view shown here. This value was found to be consistent among the unexposed portions of each specimen, so it seems reasonable to assume a similar thickness on the as-treated test face of each specimen as well. Although not analytically confirmed in this investigation, 
the outermost portion of the M-layer that etched relatively dark in Fig. 2 is about half (16-20 $\mu \mathrm{m})$ of the total M-layer thickness and corresponds to the so-called compound zone that is primarily epsilon iron nitride. (Melonite $®$ literature also refers to this as a "white layer" which, if etched differently, might well be a descriptive characteristic of this relatively corrosion-resistant layer.) The remainder of the M-layer - not as heavily etched here - is likely to be the diffusion zone where there is an elevated nitrogen content but not sufficiently high to form the iron nitride. Note also in Fig. 2 the slip lines within the M-layer material and (fewer) in the substrate immediately adjacent to the M-layer; these suggest significant lattice deformation/stress and hardening associated with grossly exceeding the equilibrium solubility of nitrogen within the austenite lattice. The remainder of the $316 \mathrm{LN}$ stainless steel substrate is comprised of equiaxed austenite grains with little evidence of grain boundary precipitation resulting from the heat treatment associated with M-layer application.

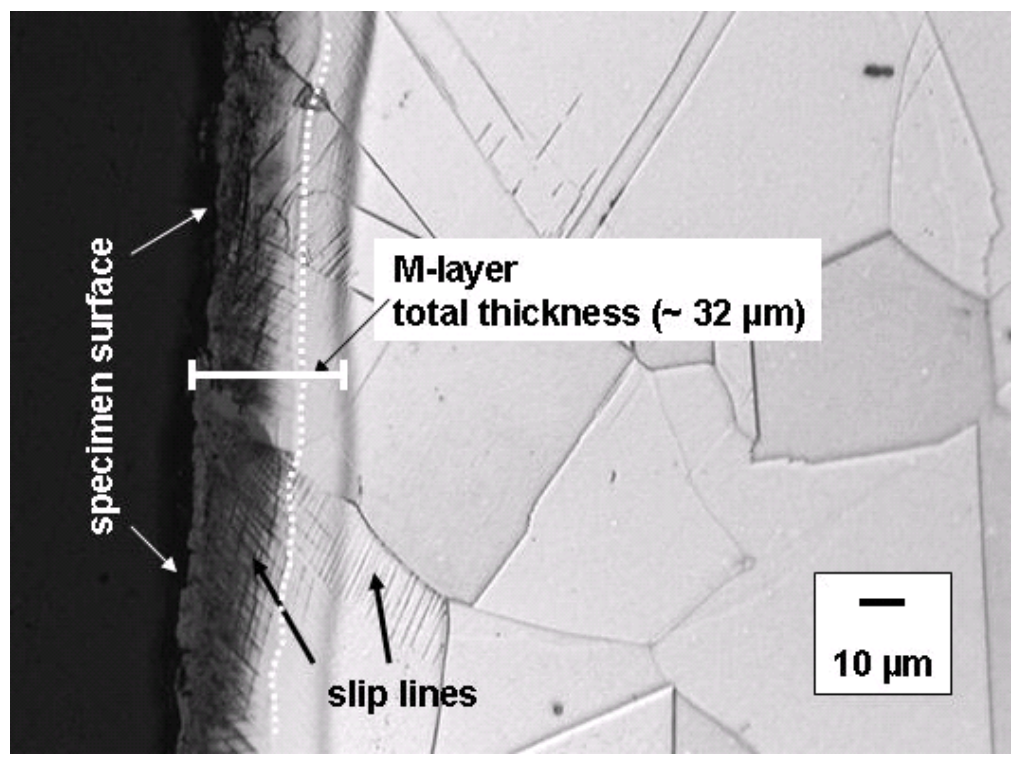

Fig. 2. Cross-section of the side of a $316 \mathrm{LN}$ cavitation specimen following M-layer treatment. This particular specimen was sonicated for $12 \mathrm{~h}$ in mercury, but the side of the specimen is unaffected by the exposure and represents the as-treated specimen surface. Etched with glyceregia. (Met. photo 09-1020-16.)

For total sonication periods less than about six hours, the primary visual result on the specimen test surface is the appearance of scattered shallow craters such as those depicted in Fig. 3. While the craters are generally circular in shape, they are different than 
typical craters observed on untreated $316 \mathrm{LN}$ specimens in that they are essentially flatbottomed (instead of hemispherical and very rough) and each one is approximately the same depth - about $20 \mu \mathrm{m}$ - upon initial formation. Based on the metallographic result shown in Fig. 2, it would appear that the outer portion of the M-layer - about $20 \mu \mathrm{m}$ thick is the first to fail and that the failure occurs at least in part by loss of adhesion between the compound layer and the diffusion layer. It is possible that a complex residual stress pattern across this apparent interface contributes to failure at this location. The remainder of the test surface - the bottom of any shallow craters as well as the uncratered surfaces exhibited a profile of only about 5-6 $\mu \mathrm{m}$.
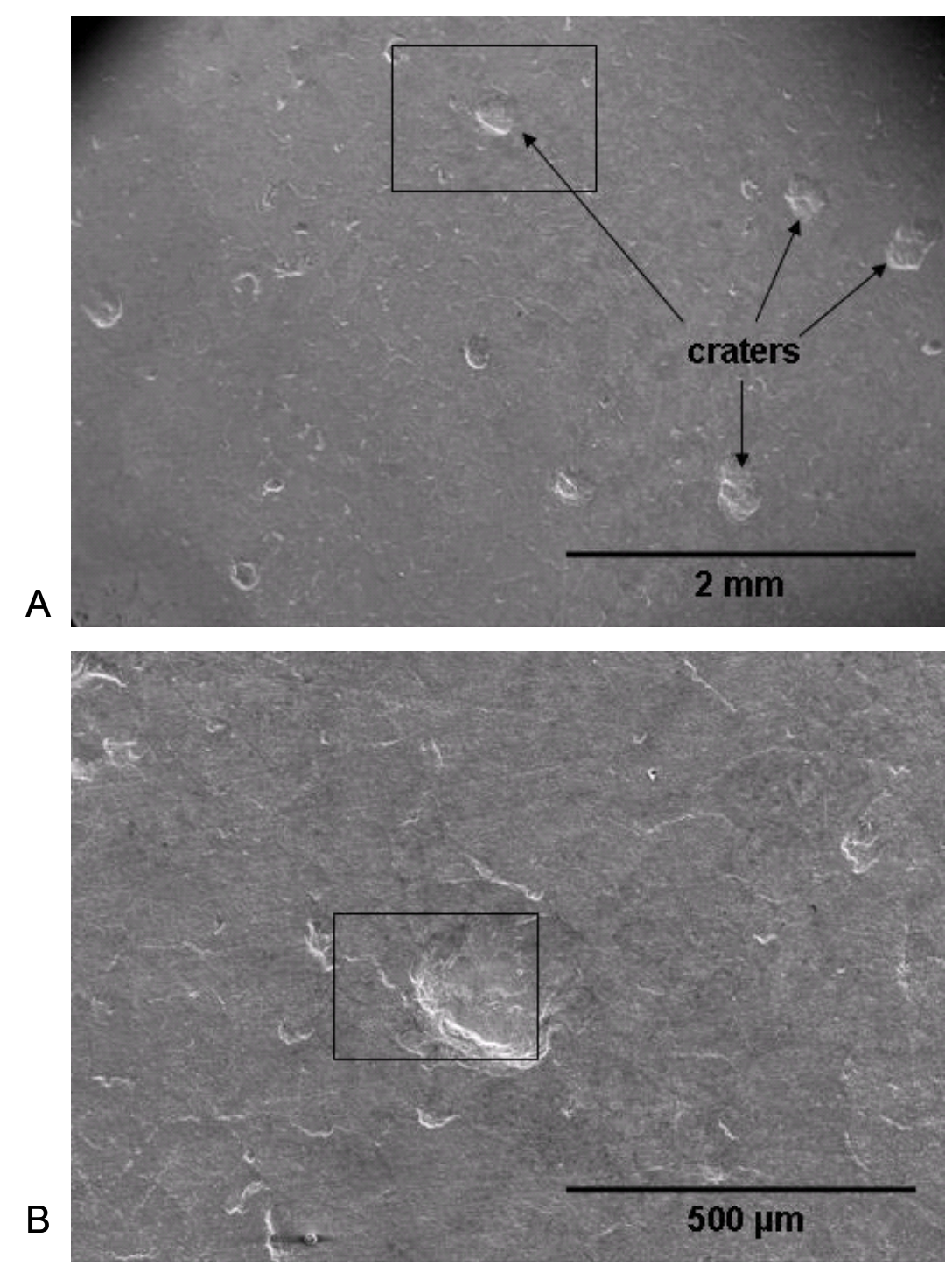

Fig. 3. Continued on next page. 

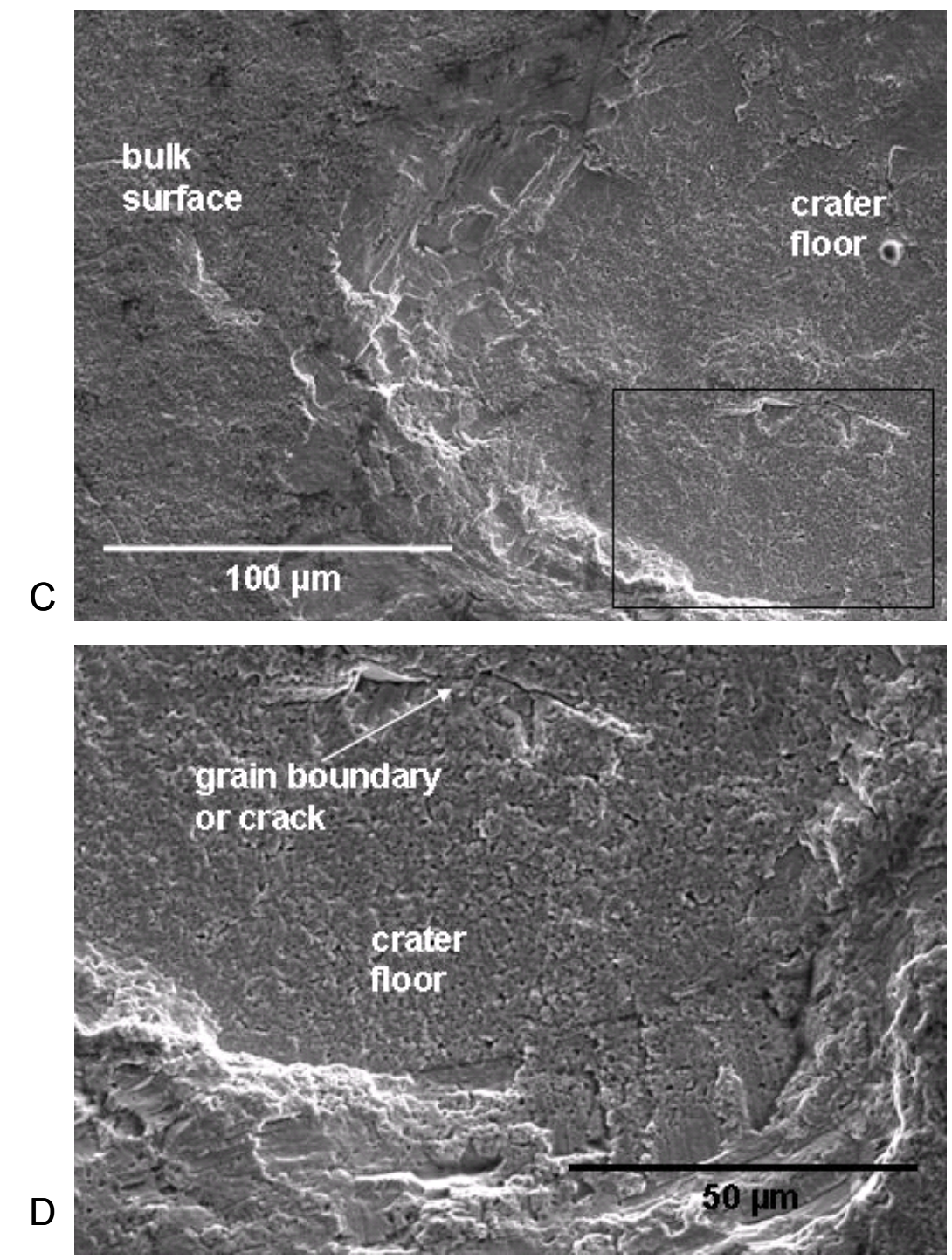

Fig. 3. SEM images of the $316 \mathrm{LN}+\mathrm{M}$-layer test surface following $1 \mathrm{~h}$ sonication in mercury. Black highlight boxes denote area viewed at higher magnification in the following photo in the series. (Met. photos VP2522 -01, -03, -05, -07.

In addition to the development of shallow flat-bottomed craters relatively early in the total sonication exposure, the dark brown or black surface coloration of the test piece was quickly lost from the sonicated surface. Figure 4 is representative of this observation, which shows a substantial change within the first hour of sonication. In addition, the photograph shows the substantial increase in the number of shallow craters (relatively shiny spots on the somewhat darker test surface) observed upon increasing total exposure from 1 to $3 \mathrm{~h}$. 
Even after $3 \mathrm{~h}$ exposure, however, no large hemispherical craters have completely penetrated the M-layer.

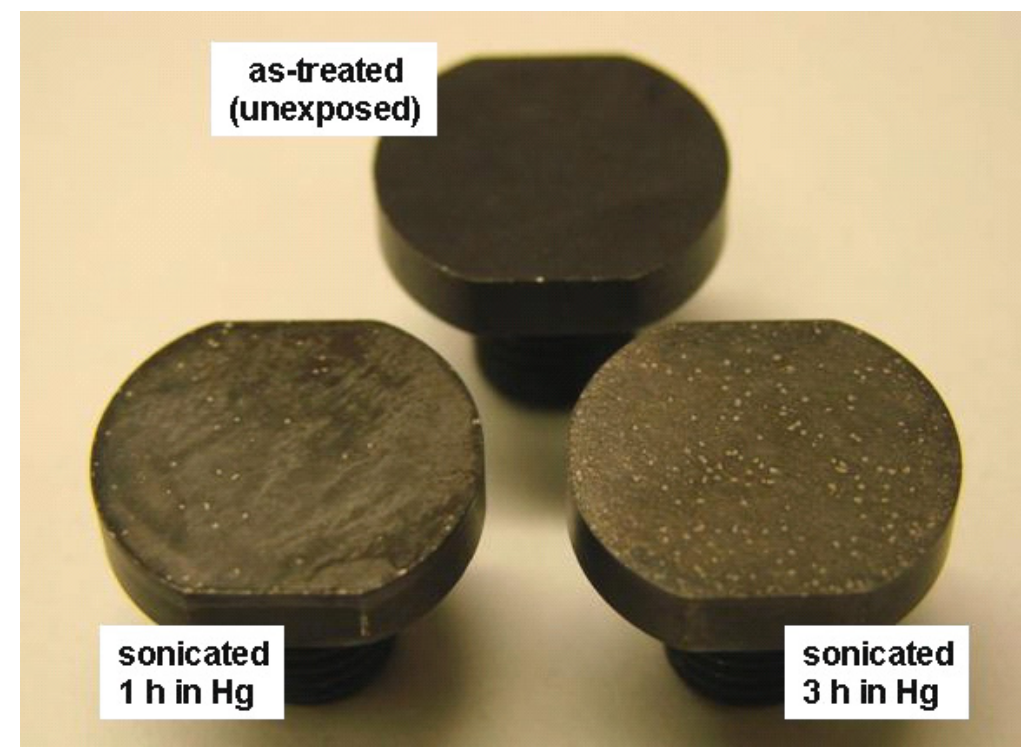

Fig. 4. As-treated (unexposed M-layer) test surface compared to surfaces following 1 - and 3-h sonication exposures in mercury. For scale, note that the full diameter of the test button surface is $16 \mathrm{~mm}$.

Figure 5 is representative of the observation that grain boundaries of the M-layer surface - which become distinguished during total exposures in the range of 3-9 $\mathrm{h}$ by grooving/cracking - appear to be more susceptible to cavitation-erosion damage than the bulk surface. The reason perhaps relates to more rapid precipitation kinetics (for nitrides or carbides or both) at grain boundaries compared to the grain interior, thus tending to form relatively brittle precipitate interfaces during the treatment procedure.

Hemispherical craters of sufficient depth to penetrate the full thickness of the M-layer were first observed after $4.5 \mathrm{~h}$ exposure on one specimen and after $7.5 \mathrm{~h}$ exposure on the other. Only modest numbers (6-10 on each specimen) of large hemispherical craters were apparent until about $12 \mathrm{~h}$ exposure, at which point they were observed in numbers sufficient to make tracking the advance of individual craters very difficult. Figure 6 shows a representative specimen surface following $12 \mathrm{~h}$ total sonication time. At this point in the cavitation-erosion process, craters that develop are roughly hemispherical with surfaces that are substantially rougher than those observed earlier in the cavitation process (contrast to 
Fig. 3) and indeed are comparable to surfaces observed when craters develop on annealed and untreated 316LN specimens. ${ }^{7-9}$ Also at about 12-14 h total exposure time, relatively little of the initially smooth $(\sim 5 \mu \mathrm{m})$ and protective M-layer was observed remaining on the test surfaces.

A

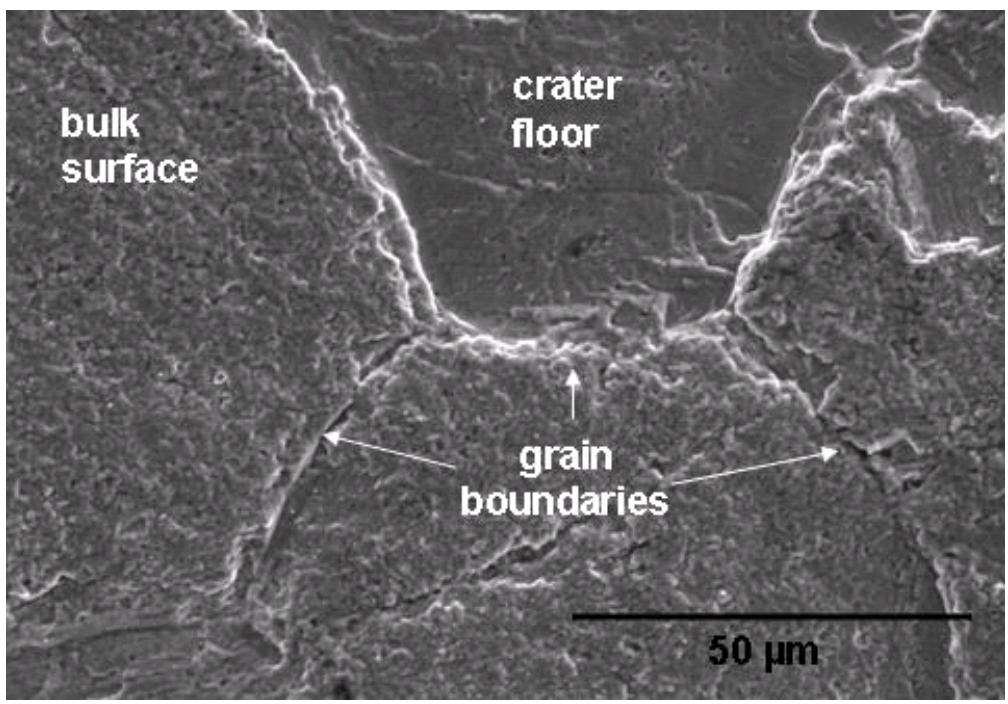

$B$

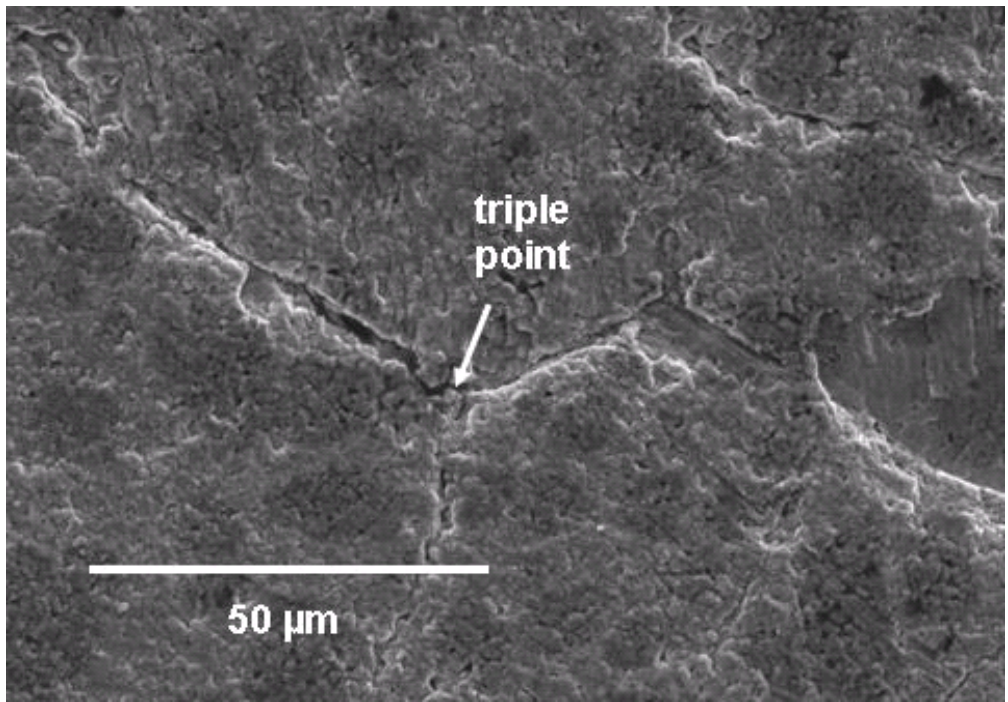

Fig. 5. SEM images of the $316 \mathrm{LN}+\mathrm{M}$-layer test surface following (a) $3 \mathrm{~h}$ and (b) $6 \mathrm{~h}$ sonication in mercury. (Met. photos VP2530-11 and VP2544-15.)

Following exposures in which the original M-layer (at full thickness, or after partial failure that resulted in flat-bottom craters with about $15 \mu \mathrm{m}$ of M-layer remaining) had not been removed from the test surface, it was observed that mercury did not remain wetted to the 
post-test surface for more than a few minutes when exposed to air. However, mercury was found to tenaciously wet (and remain wetted for extended times) the surfaces of the hemispherical craters in which substrate 316LN was exposed. Figure 7 is representative of this observation, which shows a post-test surface (prior to cleaning) following $12 \mathrm{~h}$ exposure. The mercury remained adherent to essentially all of the deep crater surfaces but no longer wet any other surfaces.
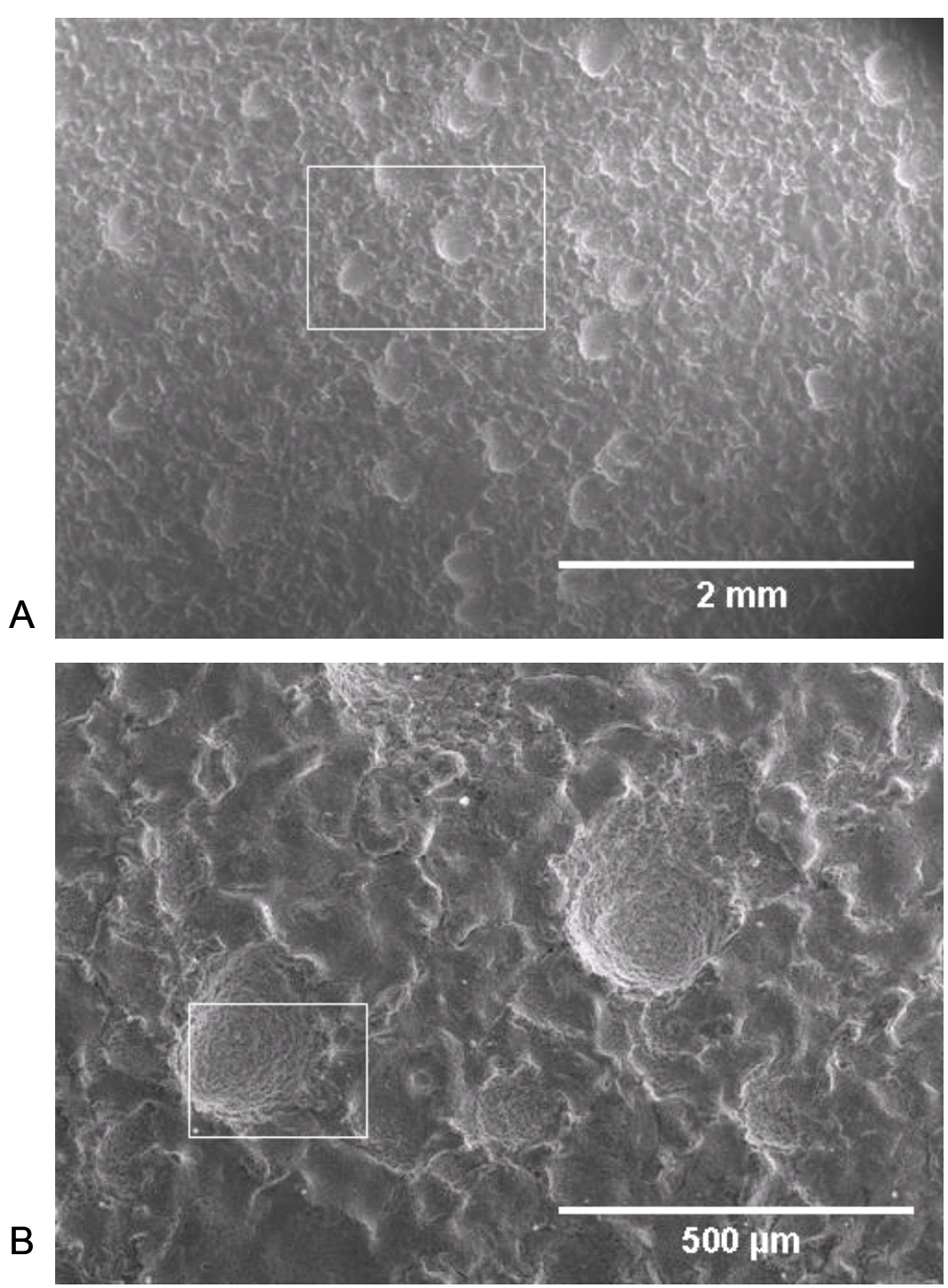

Fig. 6. Continued on next page. 

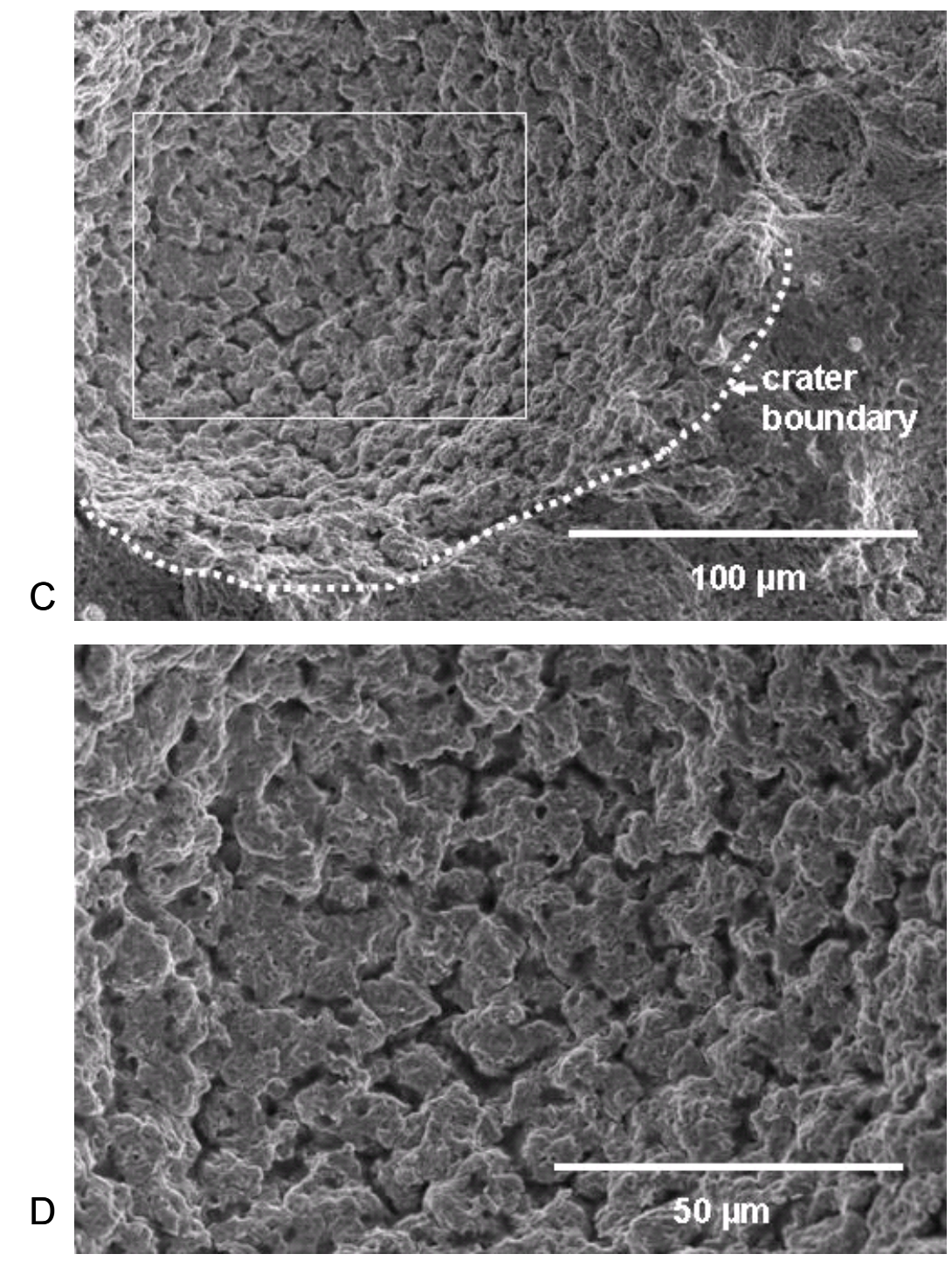

Fig. 6. SEM images of the 316LN + M-layer test surface following $12 \mathrm{~h}$ sonication in mercury. White highlight boxes denote area viewed at higher magnification in the following photo in the series. (Met. photos VP2563-01, -03, -05, -06.) 


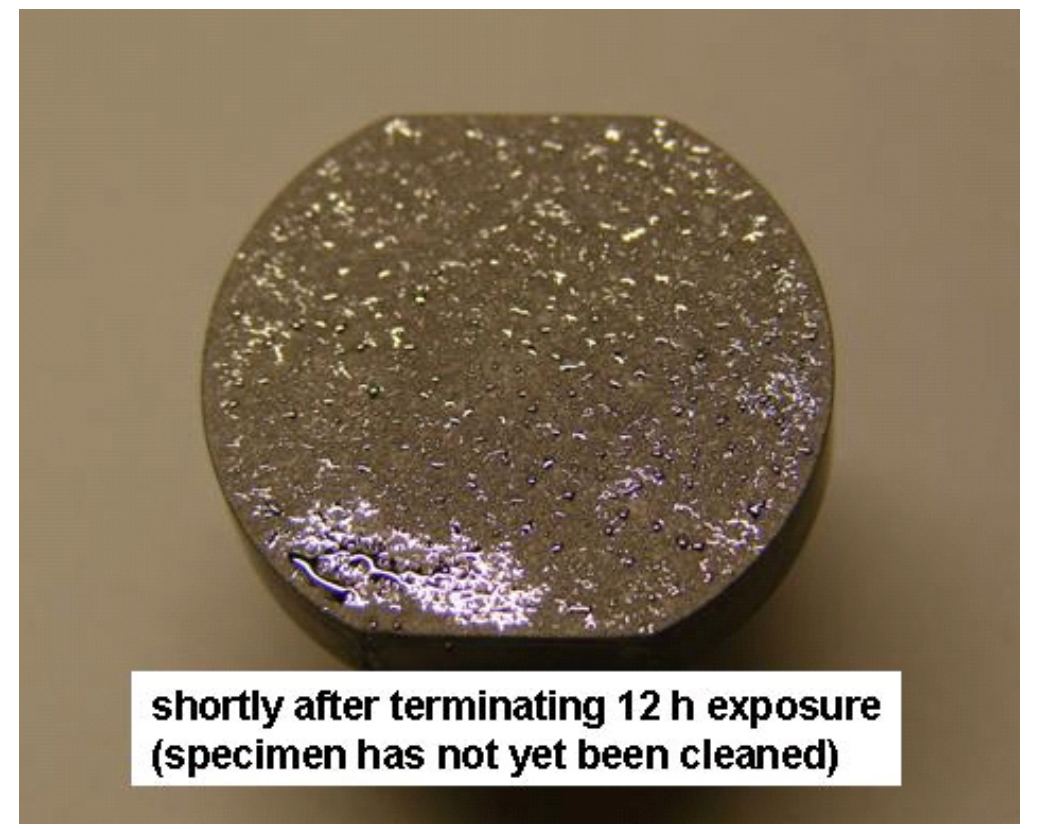

Fig. 7. Cavitation test surface showing mercury remaining at locations sufficiently cratered to penetrate the M-layer and expose substrate $316 \mathrm{LN}$. This test button was photographed a few moments after terminating the exposure in which the total sonication time was increased to $12 \mathrm{~h}$.

Figure 8 is a series of SEM photographs of the test surface of a specimen following $20 \mathrm{~h}$ sonication. Relatively deep craters cover the test surface and in some cases overlap slightly. At this point in the exposure process, the weight loss per hour has accelerated from approximately $2.5 \mathrm{mg} / \mathrm{h}$ (observed until large craters became dominant on the test surface) to approximately $5.5 \mathrm{mg} / \mathrm{h}$. This value is still substantially less than that observed for annealed and untreated $316 \mathrm{LN}$ (near $12 \mathrm{mg} / \mathrm{h}$ ). The reason relates to the fact that some fraction of the surface area remains partially protected by residual M-layer and that nitrogen diffusion into the substrate perhaps slightly hardens and thus improves cavitation-erosion resistance even deeper into the specimen than the apparent extent of the M-layer based on metallography. 

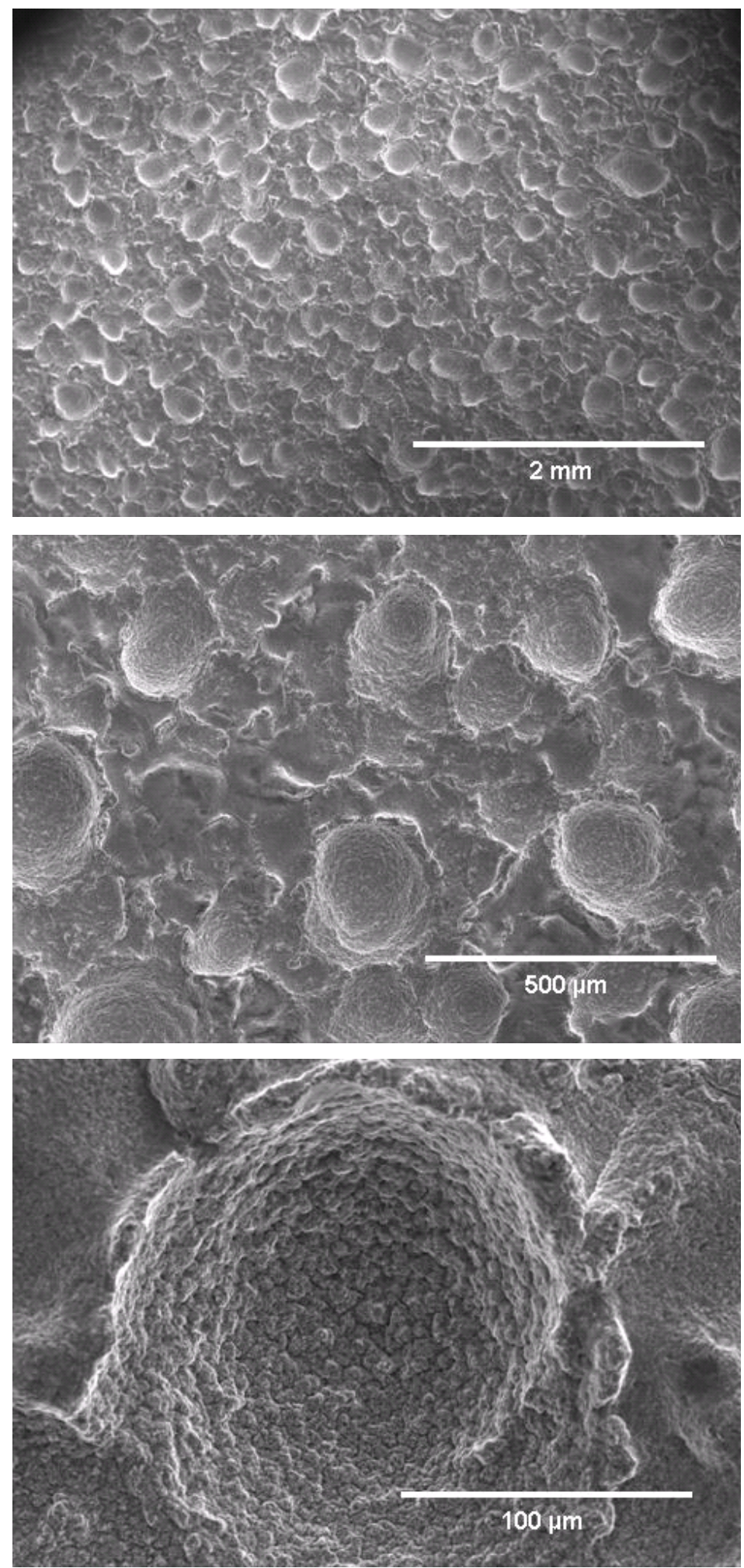

Fig. 8. SEM images of the 316LN + M-layer test surface following $20 \mathrm{~h}$ sonication in mercury. (Met. photos VP2632-01, -07, -23.) 
Figure 9 is a polished and etched cross section representing the specimen sonicated for $12 \mathrm{~h}$ prior to being sectioned for metallography. At the left end of the photograph, the side of the specimen is visible. Although the entire specimen surface received the M-layer treatment, the sides are not affected during sonication and thus represent the "as deposited" condition of the M-layer. A higher magnification of the highlighted area on the side appeared in Fig. 2, which showed the structure and thickness of the original M-layer.

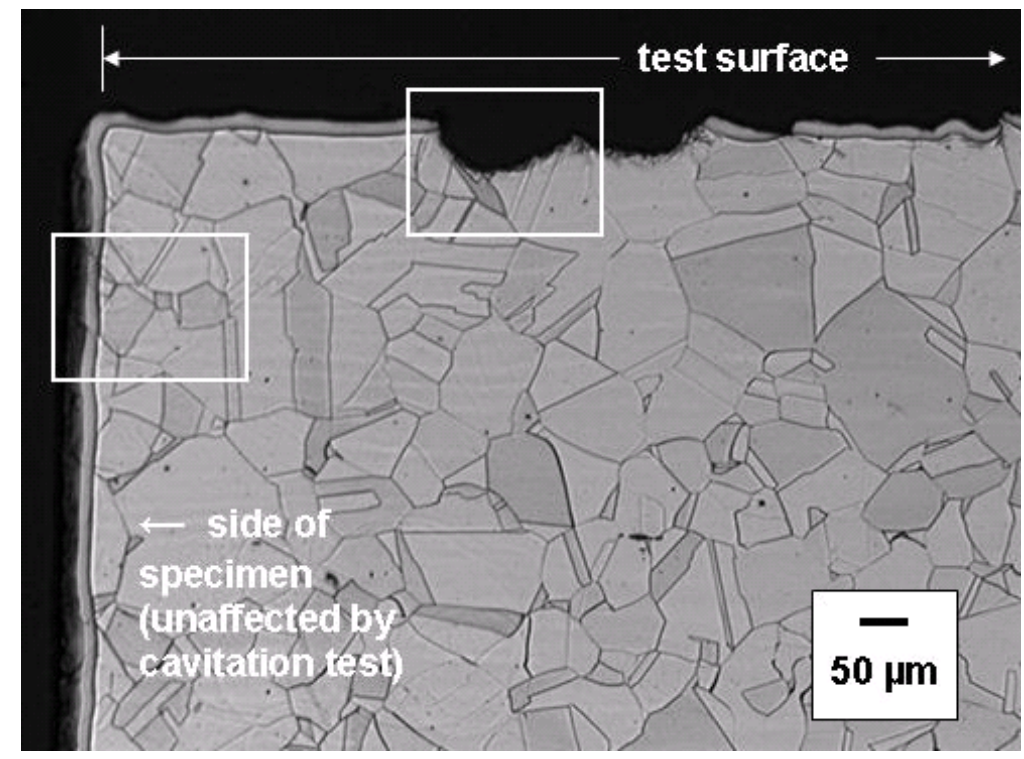

Fig. 9. Cross section of test specimen following $12 \mathrm{~h}$ sonication in mercury. Etched with glyceregia. (Met photo 09-1020-12.)

The specimen test surface is shown along the top of Fig. 9. After $12 \mathrm{~h}$ sonication, it is readily apparent that the $\mathrm{M}$-layer has been breached to expose the substrate in some areas. In particular, in the highlighted area on the specimen surface, note the shape of a roughly hemispherical crater approximately $60 \mu \mathrm{m}$ deep in this view. At higher magnification (Fig. 10), it can be seen that the residual M-layer thickness adjacent to the crater is about $16 \mu \mathrm{m}$ and still apparently protective (no change in the substrate), while the bottom surface of the crater reveals slip lines deep within the substrate indicative of substantial plastic deformation associated with the cavitation-erosion process. Note that slip lines associated with application of the M-layer are routinely limited to the M-layer itself and are periodically observed (e.g., see Fig. 2) penetrating a few $\mu \mathrm{m}$ into the underlying substrate. Slip lines associated with the cavitation process appear much deeper into the substrate and tend to 
surround craters in the test specimen surface, but are rarely observed in areas without craters.

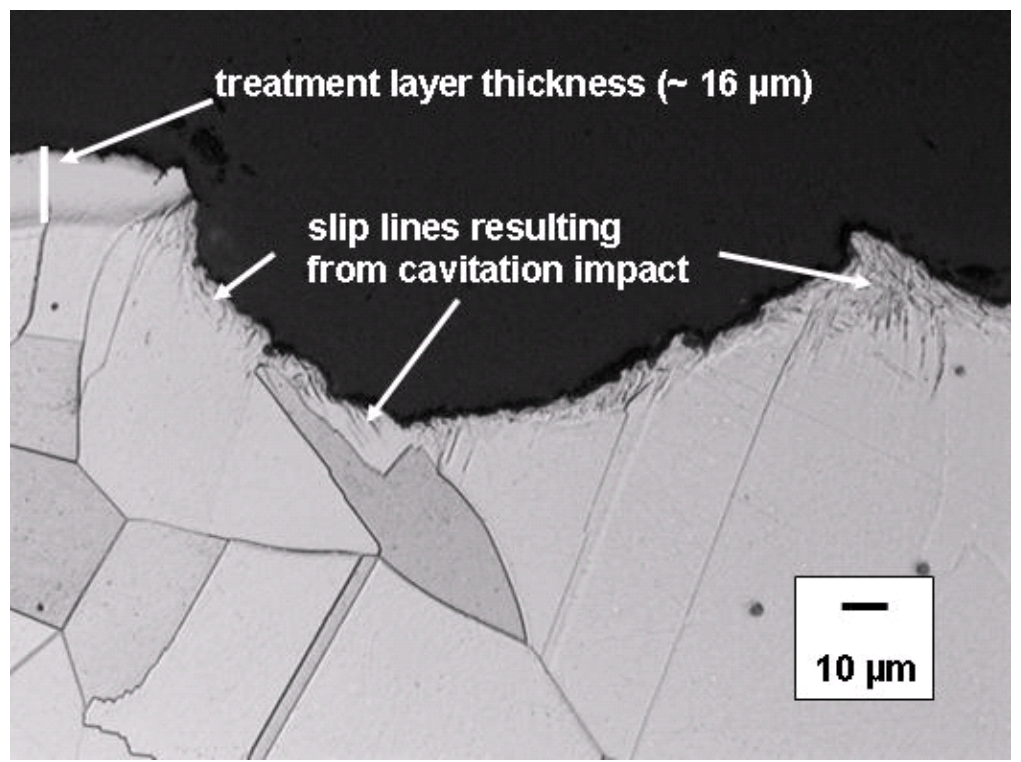

Fig. 10. Higher magnification view of the surface crater indicated in the white highlight box from Fig. 9. (Met. photo 09-1020-22.)

Figure 11 is a view of another surface location on the specimen sonicated for $12 \mathrm{~h}$. Here, the M-layer has been breached, exposing the substrate to mercury but this location may represent the extreme edge of a crater or a crater may not have formed (yet) at this location. In any case, this view serves to further associate a relatively high concentration of slip lines in the substrate (compared to the modest concentration beneath the remaining $\mathrm{M}$ layer) with the physical deformation of breaching the M-layer and incipient crater formation, while the remaining M-layer itself is relatively resistant to the forces associated with cavitation void collapse. A further testament to the violence of the cavitation-erosion process appears in Fig. 12, which shows yet another location on the surface of the specimen sonicated $12 \mathrm{~h}$ and reveals - in addition to a high concentration of slip lines - an M-layer eroded to variable degree, a highly twisted/deformed surface (yet no cracks form along the interface between substrate and M-layer), and cracks in both the M-layer and substrate. The latter observation suggests the mechanism of material removal during sonication is related to initiation and coalescence of microcracks. 


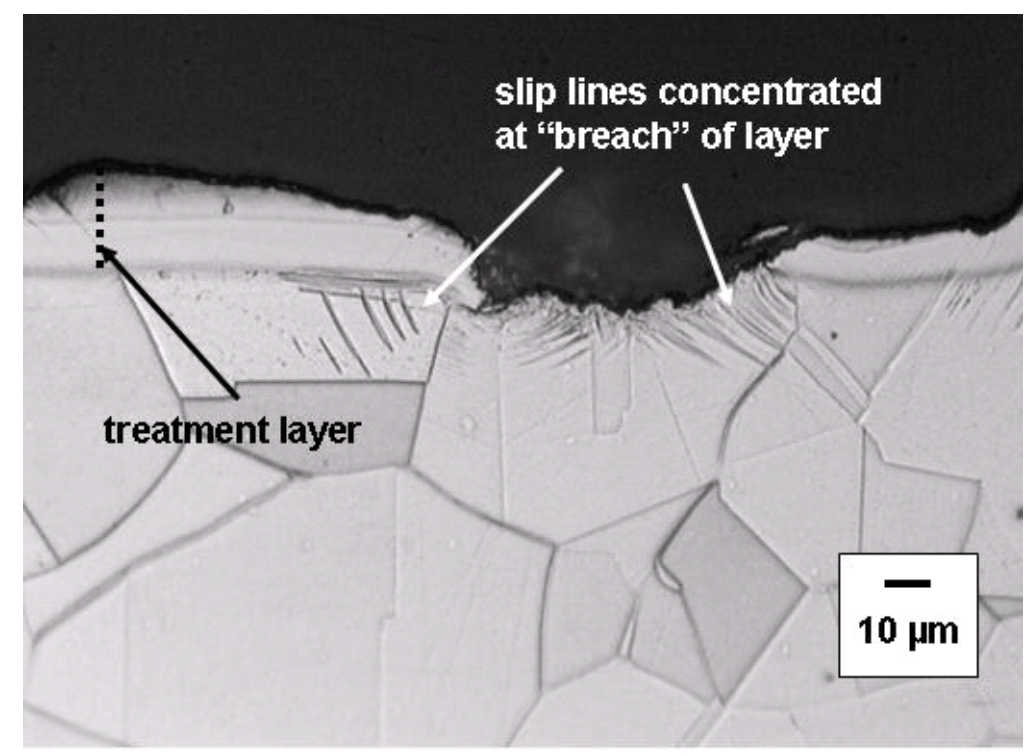

Fig. 11. Cross section of test specimen following $12 \mathrm{~h}$ sonication in mercury - a different area on the same test surface depicted in Figs. 9 and 10. Etched with glyceregia. (Met. photo 09-1020-24.)

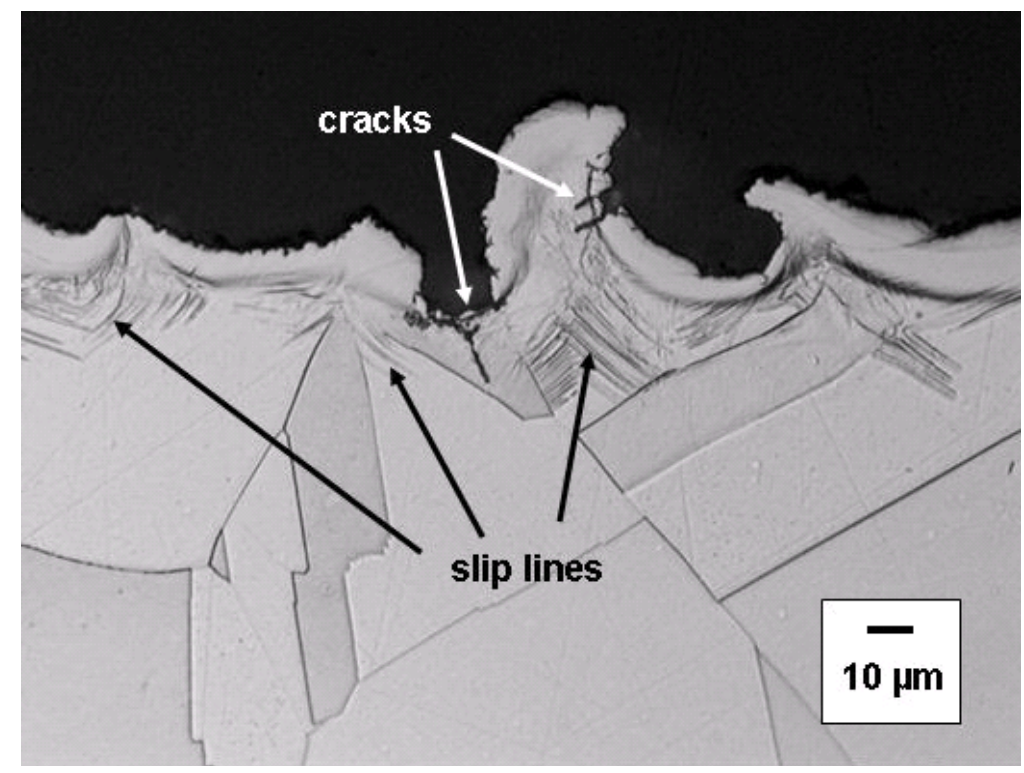

Fig. 12. Another cross section of the test specimen surface following sonication for $12 \mathrm{~h}$ in mercury. This view reveals more surface distortion resulting form the cavitation process. Etched with glyceregia. (Met. photo 09-1020-18.) 
Figure 13 includes two cross sections of different areas of the specimen sonicated $20 \mathrm{~h}$ in mercury. These photographs are representative of the observation that the primary changes in the surface as sonication time is extended are that the craters get deeper (also see Fig. 14) and sufficiently numerous that they frequently overlap, and the fraction of the test surface with any remaining M-layer decreases rapidly. The latter observation accounts for the gradual increase in weight loss per unit time associated with the sonication process, with eventually a complete transition from M-layer properties to untreated $316 \mathrm{LN}$ when all of the residual M-layer has been eroded/removed from the surface.

Once the M-layer is sufficiently compromised that craters can progress into the substrate $316 \mathrm{LN}$, the craters increase in depth relatively rapidly as shown in Fig. 14, which records the depth of eight specific/individual craters on two different specimens beginning at the end of the exposure period in which they were first observed on the post-test surface. The range of crater depth at first observation was 34-90 $\mu \mathrm{m}$, which no doubt depends primarily on whether the M-layer was breached early or late within a particular exposure interval. The average rate of increase in crater depth (the slope of the dotted line in Fig. 14) is about $11 \mu \mathrm{m} / \mathrm{h}$, which is somewhat less than the value of $15-20 \mu \mathrm{m} / \mathrm{h}$ associated with untreated $316 \mathrm{LN} .{ }^{8}$ The slightly lower rate of crater growth in the nitro-carburized material might be related to modest hardening resulting from interstitial diffusion deep into the material (considerably deeper than is apparent from the metallographic extent of penetration). 

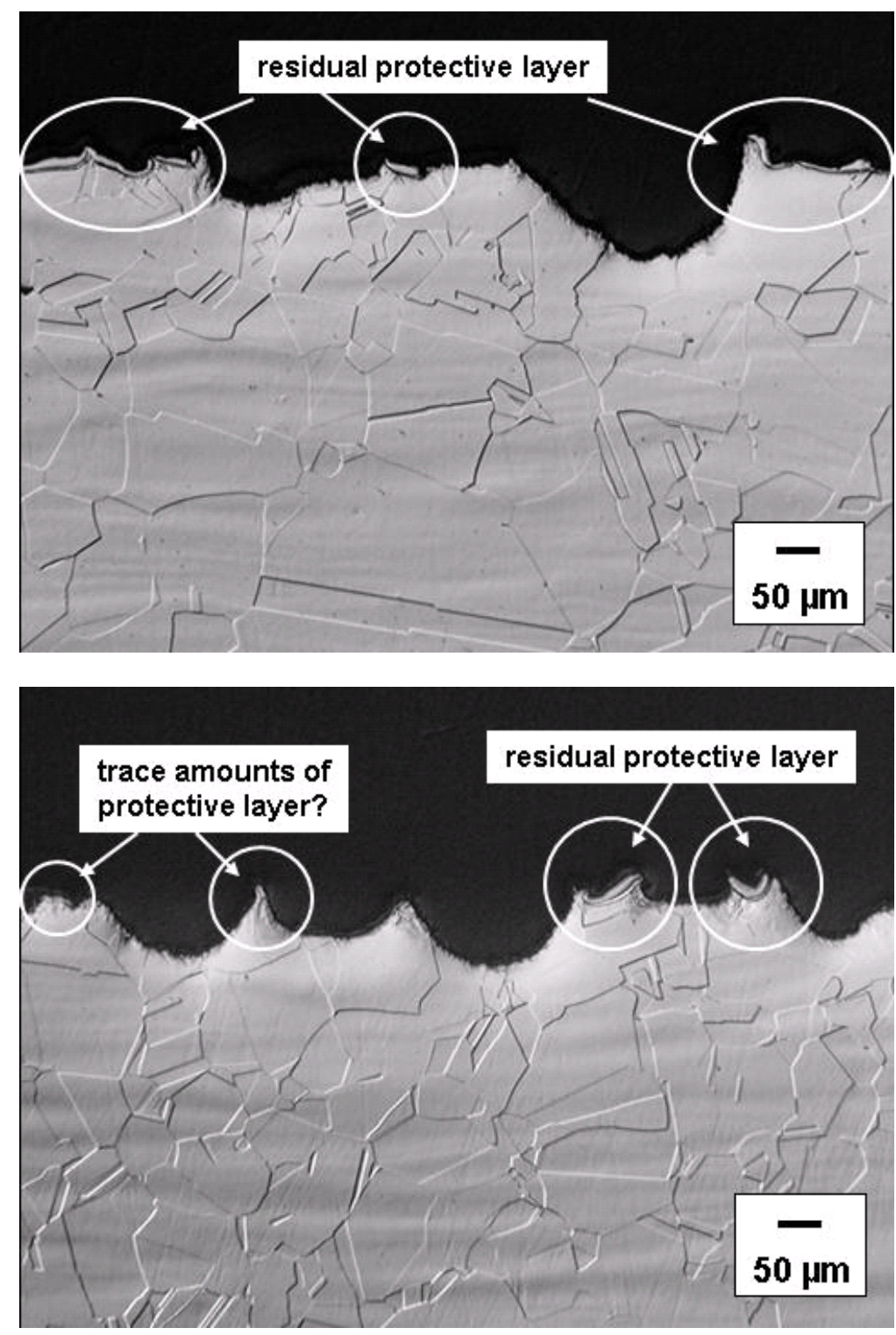

Fig. 13. Cross sections of test specimen following $20 \mathrm{~h}$ sonication in mercury. Etched with glyceregia and viewed with differential interference contrast light. (Met photo 09-1405-16, -19.) 


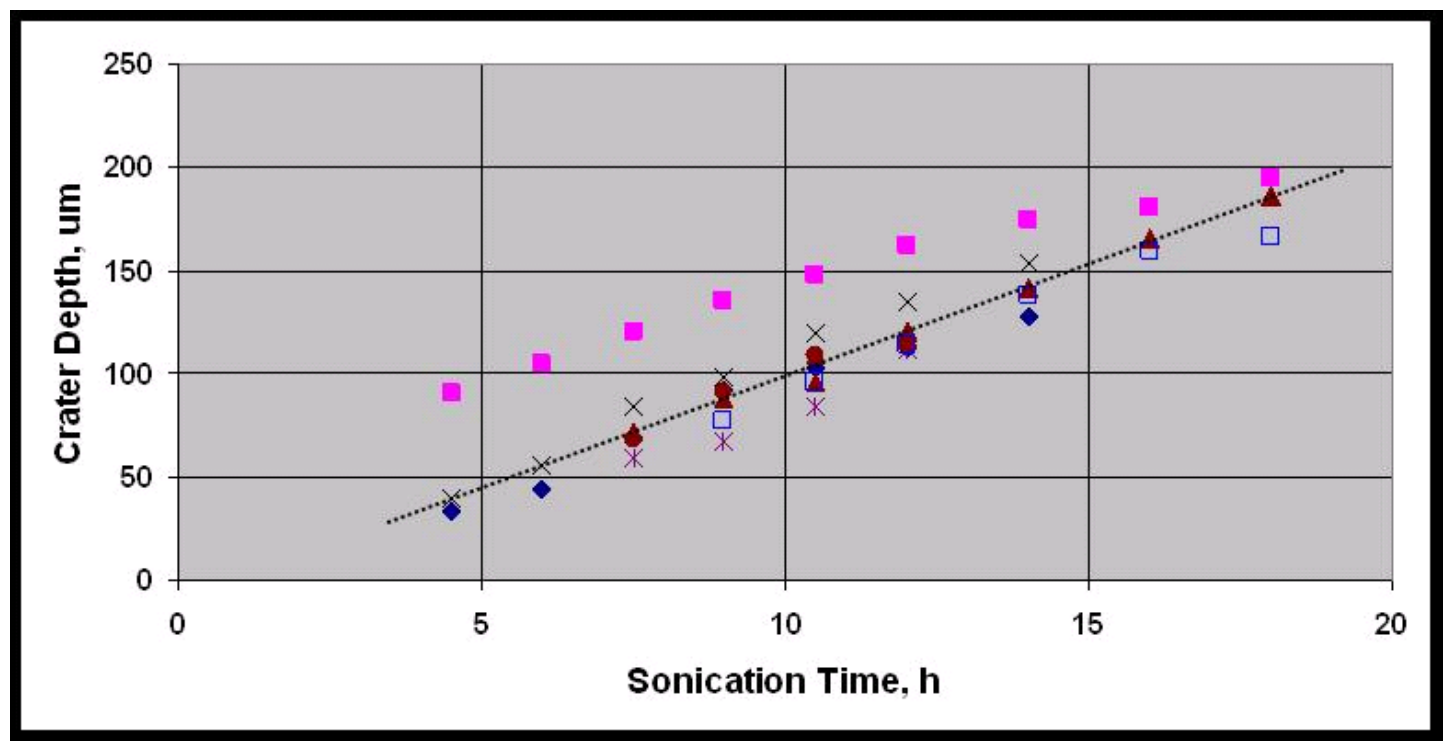

Fig. 14. Depth as a function of sonication time in mercury for eight individual craters.

Figure 15 compares the relative cavitation-erosion resistance - in terms of total weight loss on identically sized specimens - of annealed/untreated 316LN with that of several surface treatments, including the K-layer ${ }^{8-9}$ and M-layer (both nominally $33 \mu \mathrm{m}$ in depth), a dual treatment that incorporated adding a nitriding treatment to the K-layer (termed $\mathrm{K}+\mathrm{N}$ layer, ${ }^{11}$ and a standard nitriding treatment. ${ }^{12-13}$ Among these, the K-layer seems to provide superior performance for the cavitation conditions of these tests in mercury, as evidenced by a roughly linear weight loss associated with erosion that was about a factor of three lower than that observed for the M-layer treatment. In addition, and the protective qualities of the K-layer persisted to somewhat longer sonication treatment times than those of the M-layer prior to gradual failure to a performance level approximating that of the untreated material. The M-layer, while not as protective as the K-layer for the somewhat unique/unusual sonication conditions in mercury imposed in the vibratory horn test, nevertheless was observed to impart substantial cavitation-erosion resistance to the untreated material and is somewhat superior to the $\mathrm{K}+\mathrm{N}$ layer treatment. Note also in Fig. 15 that the M-layer - despite designation as a nitro-carburizing treatment, implying a mixture of nitrogen and carbon penetrating into the surface - reveals weight loss characteristics during sonication in mercury very similar to those of a purely nitrided surface layer examined previously. ${ }^{12-13}$ 


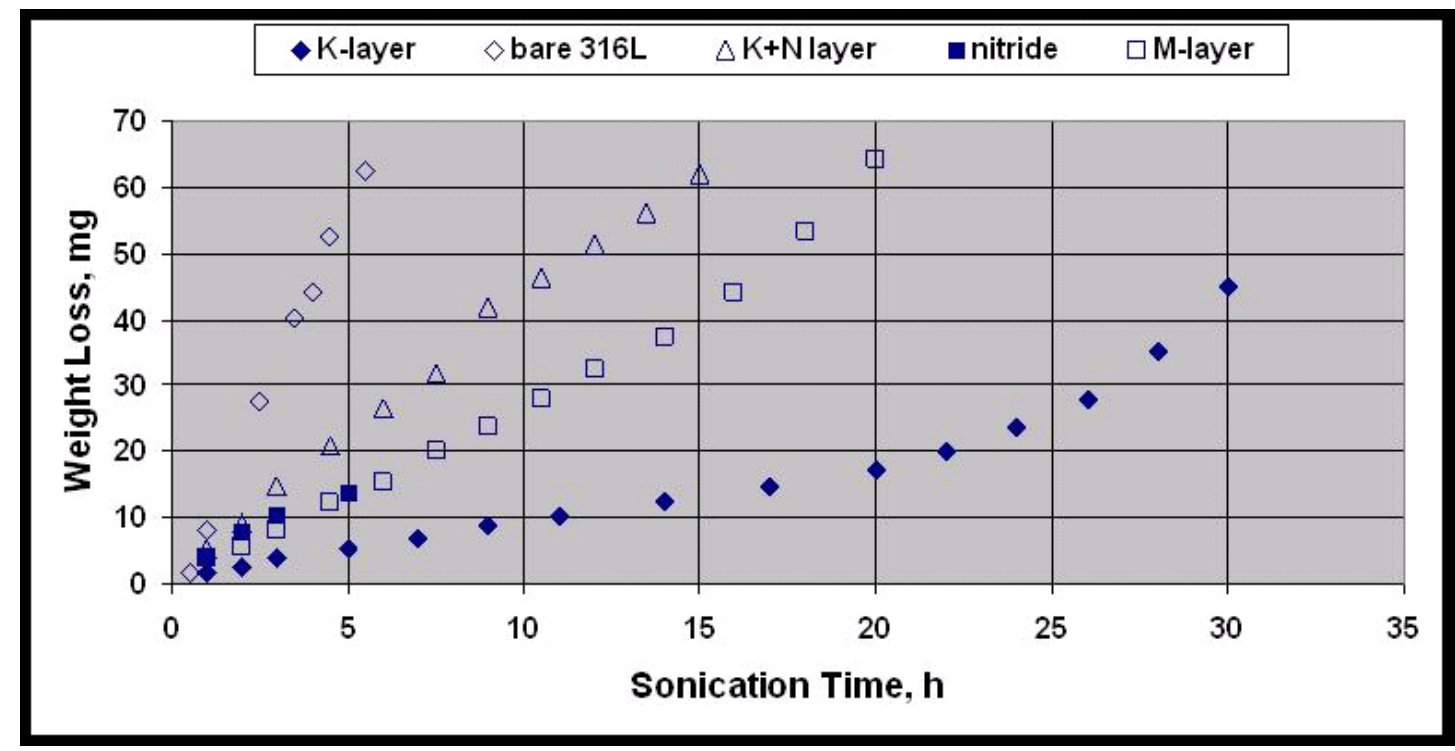

Fig. 15. Comparison of total weight loss as a function of sonication time in mercury for bare/untreated 316LN stainless steel and for the same alloy with different surface treatments.

The reason for the difference in performance between the M-layer (nitrogen diffused into the substrate) and the K-layer (carbon diffused into the substrate) is not straightforward. Figure 16 shows hardness profiles associated with the M-layer and the K-layer, and within the scatter of the technique and ability to assess such thin layers adequately, they are very similar. The data in Fig. 16 suggest that the K-layer is perhaps somewhat harder at the outermost portion of the protective layer $(<10 \mu \mathrm{m}$ from the surface), but it is not clear if limited hardness data for the M-layer contribute disproportionately to that assessment. Further, data for nitriding following carburizing of 316LN shows the outermost surface to have a hardness of 1000-1200 DPH. ${ }^{11}$ Note hat for extended depth into the specimen $(>40 \mu \mathrm{m})$, there appears to be a modest hardness increase associated with application of the M-layer. This supports previous comments associated with Fig. 14, in which it was speculated that crater depth as a function of sonication time was impeded somewhat (compared to untreated material) by slight hardening to an extended depth within the material. 


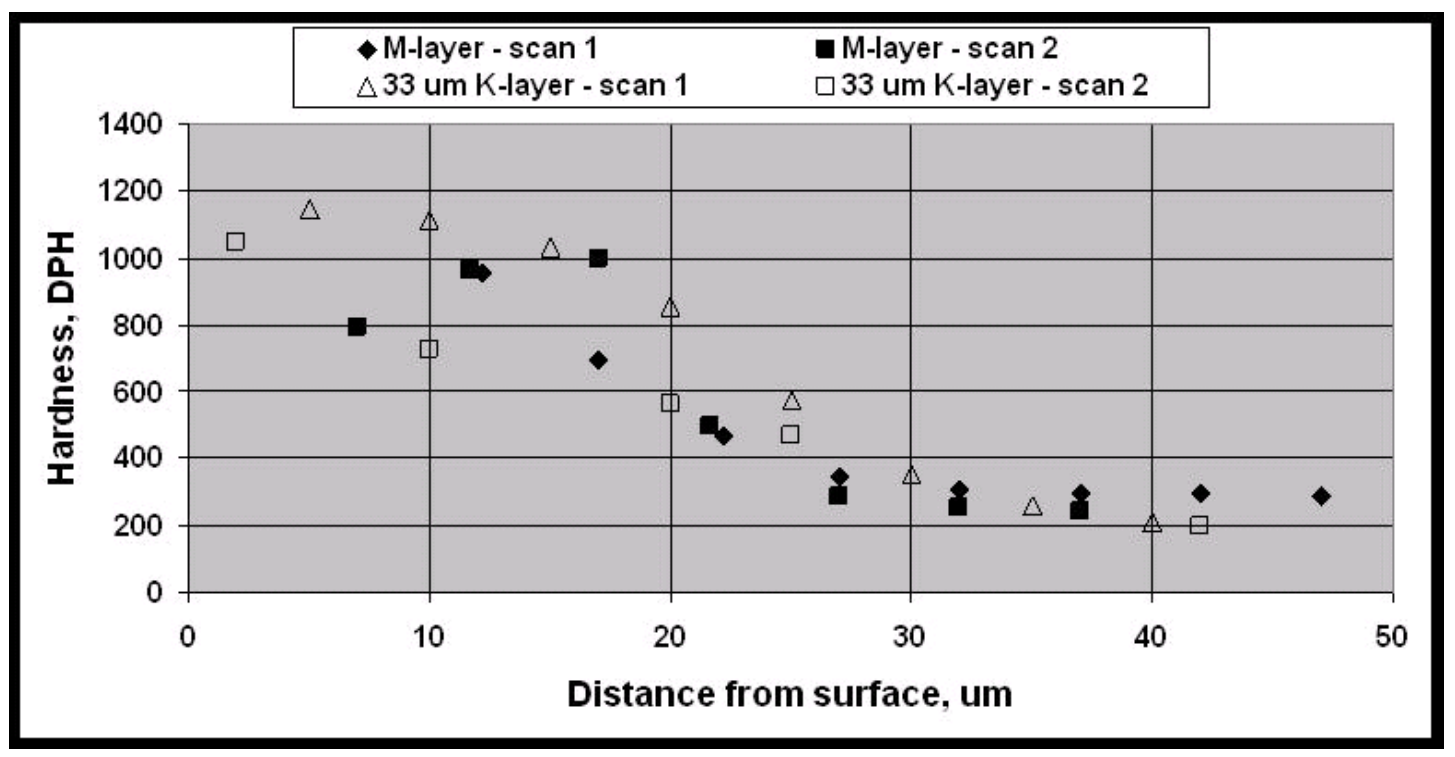

Fig. 16. Diamond Pyramid Hardness (DPH) as a function of distance from the surface for M-layer and K-layer treatments. Data for K-layer adapted from ref. 14. Measurements with $50 \mathrm{~g}$ load.

Ultimately, as has been noted previously, ${ }^{7,}{ }^{15}$ bulk hardness is not a stand-alone predictor of cavitation-erosion resistance in mercury. A combination of toughness/ductility as well as strength and hardness is required. It would appear that a super-saturation of carbon in the austenite lattice near the surface is somewhat superior to a super-saturation of nitrogen in that regard, but the details of the mechanism of relative resistance have not been determined as yet. 


\section{SUMMARY AND CONCLUSIONS}

The Melonite $®$ surface hardening process was applied to type $316 \mathrm{LN}$ stainless steel test pieces which were subsequently sonicated in mercury using a vibratory horn technique. Based on etching characteristics of the microstructure, the Melonite ${ }^{\circledR}$ treatment resulted in the formation of a surface consisting of a distinct outer layer about $20 \mu \mathrm{m}$ thick that is primarily iron nitride and an inner layer about 12-15 $\mu \mathrm{m}$ thick substantially enriched in solidsolution nitrogen. During sonication, the protective layer initially failed at the interface between the outermost epsilon nitride layer and the solid-solution nitrogen diffusion zone. Extended sonication gradually eroded the remaining protective layer which was eventually breached, with concurrent development of roughly hemispherical craters similar in appearance to those that form in untreated 316LN. At least initially, these craters became deeper at a rate similar to but slightly less than for untreated material, suggesting a modest effect of hardening due to solid solution nitrogen in the structure that was deeper than the metallographic appearance might indicate.

Cavitation-erosion results compared with other surface treatments indicate that specimens treated with Melonite $®$ perform similarly to specimens treated with a simple nitriding process. Neither the nitriding nor Melonite ${ }^{\circledR}$ treatment is quite as effective as a previously evaluated low temperature carburizing treatment, the latter being about a factor of three better in terms of weight loss during sonication in mercury. 



\section{ACKNOWLEDGMENTS}

Funding for this investigation was provided by the Spallation Neutron Source Project at Oak Ridge National Laboratory through work managed by B. W. Riemer. H. F. Longmire performed the coupon metallography and T. M. Brummett performed the scanning electron microscopy reported herein. J. R. DiStefano, B. W. Riemer, and J. A. Wang reviewed the manuscript. F. C. Stooksbury helped prepare and distribute the final document. 



\section{REFERENCES}

1. K. Kikuchi, et al., "R\&D on Mercury Target Pitting Issue," J. Nucl. Mater., 318 (2003) 84.

2. B. W. Riemer, et al., "SNS Target Tests at LANSCE-WNR in 2001 - Part I," J. Nucl. Mater., 318 (2003) 92.

3. J. D. Hunn, B. W. Riemer, and C. C. Tsai, "SNS Target Tests at LANSCE-WNR in 2001 - Part II," J. Nucl. Mater., 318 (2003) 102.

4. R. Garcia, F. G. Hammitt, and R. E. Nystrom, "Correlation of Cavitation Damage with Other Material and Fluid Properties,"in Erosion by Cavitation or Impingement, ASTM STP 408, American Society for Testing and Materials (1976) 239.

5. M. D. Kass, et al., "Non-Linear Cavitation Erosion of Stainless Steel in Mercury Versus Applied Power," Tribol. Lett., 5 (1998) 231.

6. S. G. Young and J. R. Johnston, "Accelerated cavitation Damage of Steels and Superalloys in Sodium and Mercury," in Erosion by Cavitation or Impingement, ASTM STP 408, American Society for Testing and Materials (1976) 186.

7. S. J. Pawel and E. T. Manneschmidt, "Preliminary Evaluation of Cavitation Resistance of Type 316LN Stainless Steel in Mercury using a Vibratory Horn," J. Nucl. Mater., 318 (2003) 122.

8. S. J. Pawel, "Assessment of Cavitation-Erosion Resistance of 316LN Stainless Steel in Mercury as a Function of Surface Treatment," J. Nucl. Mater., 343 (2005) 101.

9. S. J. Pawel, Assessment of End-of-Life Behavior of the Surface Modification to Improve Cavitation-Erosion Resistance in the Mercury Target at the Spallation Neutron Source, Oak Ridge National Laboratory Technical Memorandum ORNL/TM2007/063, June 2007.

10. Standard Test Method for Cavitation Using Vibratory Horn Apparatus, ASTM G32-98, American Society for Testing and Materials, Philadelphia, PA (1998) 109.

11. S. J. Pawel, Comparison of Cavitation-Erosion Resistance of Carburized and Carburized-Plus-Nitrided 316LN Stainless Steel in Mercury, Oak Ridge National Laboratory Technical Memorandum ORNL/TM-2007/058, May 2007.

12. Internal Memorandum, S. J. Pawel to J. R. Haines and L. K. Mansur, "An Update on Cavitation Testing," January 2, 2004.

13. Internal Memorandum, S. J. Pawel to J. R. Haines, L. K. Mansur, and M. Futakawa, "More Information on Nitrided Specimens," March 10, 2004.

14. K. Farrell, et al., "Characterization of a Carburized Surface Layer on an Austenitic Stainless Steel," J. Nucl. Mater., 343 (2005) 123. 
15. S. J. Pawel, Assessment of Cavitation-Erosion Resistance of Potential Pump Impeller Materials for Mercury Service at the Spallation Neutron Source, Oak Ridge National Laboratory Technical Memorandum ORNL/TM-2007/033, March 2007. 


\section{INTERNAL DISTRIBUTION}
1. P. J. Blau
2. D. C. Lousteau
3. T. J. McManamy
4-6. S. J. Pawel
7. B. A. Pint

8. B. W. Riemer

9. F. C. Stooksbury

10. M. W. Wendel

11. D. F. Wilson

12. S. J. Zinkle 